\title{
Effect of Heat Input on Porosity in High Nitrogen Steel Composite Welds
}

\author{
CUI Bo ${ }^{1,2}$ ZHANG Hong ${ }^{1,3,4 a}$ and LIU Fengde ${ }^{1,4}$ \\ ${ }^{1}$ College of Mechanical and Electric Engineering, Changchun University of Science and Technology, Changchun, Jilin Province, China \\ ${ }^{2}$ College of Automible and Civil Engineering, Beihua University, Jilin, Jilin Province, China \\ ${ }^{3}$ Engineering Research Center of Laser Processing for Universities of Jilin Province, Changchun University of Science and Technology, \\ Changchun, Jilin Province, China \\ ${ }^{4}$ National Base of International Science and Technology Cooperation in Optics, Changchun University of Science and Technology, \\ Changchun, Jilin Province, China
}

\begin{abstract}
High-nitrogen steel plates with a thickness of $8 \mathrm{~mm}$ are welded with a laser-arc composite heat source for experiment to study the impact of different heat input parameters on the blowhole defect. The results show that with the increase of laser power, welding current and arc voltage, the porosity of welds decreases; with the increase of welding speed, the porosity of welds increases. Appropriately increasing the heat input helps reduce the porosity of the weld.
\end{abstract}

\section{Introduction}

High-nitrogen steel (HNS) has received extensive attention due to its good toughness and corrosion resistance [1-4]. With the development of smelting technology, HNS with a nitrogen content of more than $1.0 \%$ have been used in aviation, weapons, medical and cryogenic industries [5-6]. However, due to its own properties, high-nitrogen steels are prone to problems such as porosity, nitride precipitation, solidification cracks, and liquefied cracks during the welding process, which limits the wider application of high-nitrogen steels to some extent [7-9]. During the welding process, the solubility of nitrogen in the molten steel due to the nitrogen content of the high nitrogen steel is higher than the atmospheric pressure, so that the nitrogen element escapes and forms pores in the weld [10].

KAMIYA [11] conducted TIG welding experiments on high-nitrogen steels with nitrogen contents of $0.51 \mathrm{wt} \%$ and $0.78 \mathrm{wt} \%$. It was found that high nitrogen steel with a nitrogen content of $0.51 \mathrm{wt} \%$ did not form pores during welding. For high-nitrogen steels with a nitrogen content of $0.78 \mathrm{wt} \%$, there are a large number of tiny pores near the fusion line. Galloway A.M. [12] carried out argon arc welding on high nitrogen steels to study the effects of different proportions of nitrogen and helium in the shielding gas on the nitrogen content of the welds. The study found that when the nitrogen content of the protective gas accounted for $15 \%$, the nitrogen content in the weld increased the most. Zhao Lin et al. [13] used $\mathrm{CO} 2$ lasers to weld high-nitrogen steels with a thickness of $3 \mathrm{~mm}$. The effects of different welding heat input and different shielding gas compositions on the nitrogen content and the number of pores in the welds were studied. The results show that the higher heat input and the higher nitrogen content of the shielding gas make the tendency to produce blowholes in the weld. Miyano Y [14] used friction stir welding to weld high nitrogen steels, and studied the effect of different heat input on the microstructure and properties of welded joints. The test found that there was no porosity in the weld zone, and both the tensile strength and yield strength were higher than the base metal.

At present, there are few researches on HNS laser-arc hybrid welding, especially for the problem of pore in welding process of high-nitrogen steels [15-16]. This article focuses on the effect of heat input parameters on nitrogen content and porosity defects in welds.

\section{Experimental methods}

The test was performed using a side-axle hybrid welding system consisting of a $4 \mathrm{~kW} \mathrm{Nd:YAG} \mathrm{laser} \mathrm{(Model}$ HL4006D by TRUMPF) and a power supply (Model YD-350A G2HGE by Panasonic). The test device is shown in Fig. 1.

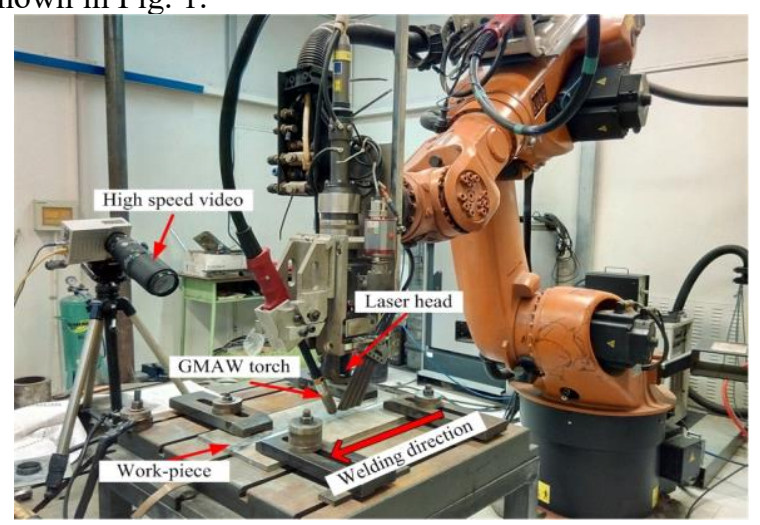

Fig. 1 Set-up of Nd:YAG laser-GMAW hybrid welding

* Corresponding author: h_zhangcust@ $126 . c 0 m$ 
The test was carried out using a flat butt welding method. The test plate size was a high-nitrogen steel plate of $8 \mathrm{~mm} \times 400 \mathrm{~mm} \times 100 \mathrm{~mm}$ with a groove angle of $30^{\circ}$, a blunt edge of $3 \mathrm{~mm}$ and a butt gap of $0.4 \mathrm{~mm}$. Filler wire uses an austenitic stainless steel wire with a diameter of $1.2 \mathrm{~mm}$. The main chemical composition of the base metal and wire is shown in Table 1. Sheilding gas is $95 \% \mathrm{Ar}+5 \% \mathrm{CO} 2$ and gas flow is $17 \mathrm{~L} / \mathrm{min}$. Welding is performed in the form of an arc in front of the laser. The laser is normally incident with an angle of $25^{\circ}$ to the torch. The main welding process parameters tested are shown in Table 2.

Table 1. Chemical compositions of base metal and filler metal (wt\%).

\begin{tabular}{|l|c|c|c|c|c|c|c|c|c|}
\hline & $\mathrm{C}$ & $\mathrm{Cr}$ & $\mathrm{Ni}$ & $\mathrm{Mn}$ & $\mathrm{Mo}$ & $\mathrm{Si}$ & $\mathrm{S}$ & $\mathrm{P}$ & $\mathrm{N}$ \\
\hline Base metal & 0.148 & 22.07 & 0.47 & 16.00 & - & 0.49 & 0.002 & 0.029 & 0.56 \\
\hline Filler wire & 0.09 & 21.0 & 9.00 & 1.6 & 0.37 & - & 0.010 & 0.020 & - \\
\hline
\end{tabular}

The X-ray detection method was used to detect the pores in the weld. N/O analyzer was used to measure the nitrogen content in the weld.

Table 2. Experimental parameters

\begin{tabular}{|l|c|}
\hline \multicolumn{2}{|l|}{ Welding parameters } \\
\hline Laser power $P[\mathrm{~kW}]$ & $2.0-2.8$ \\
\hline MAG current $\mathrm{I}[\mathrm{A}]$ & $230-270$ \\
\hline MAG voltage $\mathrm{U}[\mathrm{V}]$ & $26-30$ \\
\hline Welding speed $\mathrm{V}[\mathrm{m} / \mathrm{min}]$ & $0.6-1.0$ \\
\hline Defocusing amount $\Delta f[\mathrm{~mm}]$ & -2 \\
\hline Angle of welding torch $\theta\left[^{\circ}\right]$ & 25 \\
\hline Distance between laser and arc $\mathrm{D}_{\mathrm{LA}}[\mathrm{mm}]$ & 3 \\
\hline
\end{tabular}

\section{Results and discussion}

\subsection{Analysis of nitrogen behavior during welding}

Fig. 2 shows the change of nitrogen content in high nitrogen steel welds during welding. It can be seen from the figure that the nitrogen in the molten pool exists as nitrogen molecules, nitrogen atoms and nitrogen ions. The solubility of nitrogen in the liquid steel is relatively large, and under the effect of $95 \% \mathrm{Ar}+5 \% \mathrm{CO}_{2}$ as the welding protection gas, the bath is isolated from the air and there is no nitrogen absorption process. Because nitrogen has a lower solubility in solid steel than liquid steel, excess nitrogen escapes the weld as nitrogen in the solidification process. As the solidification process progresses, the solubility of nitrogen in the steel is dynamically changing. After the molten pool is completely solidified, the concentration of nitrogen in the steel represents a balance relationship between absorbed nitrogen and escaped nitrogen, and the nitrogen sorption process is controlled by the process that absorbs nitrogen atoms and absorbs nitrogen ions faster.

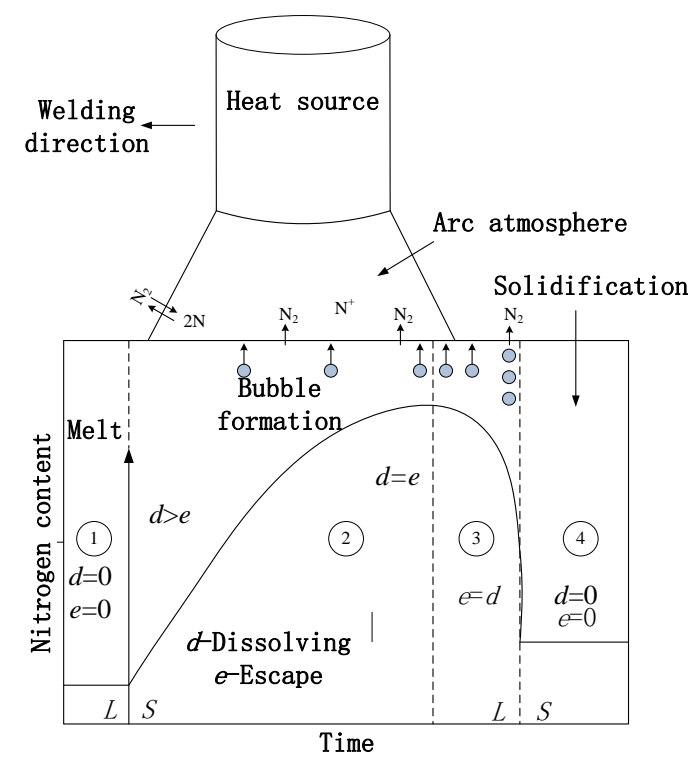

Fig. 2 A schematic diagram of the change of nitrogen content in the weld

\subsection{Effects of laser power on weld porosity}

Fig. 3 shows X-ray inspection images of high nitrogen steel welds under different laser power conditions. It can be seen from the figure that there are pores in the weld at different laser powers, and the size and number are not the same. The number of pores is significantly less at $\mathrm{P}=2.4 \mathrm{~kW}$, but the pore area is larger. The number of pores is the highest at $\mathrm{P}=2.8 \mathrm{~kW}$, and the nitrogen pores are small.

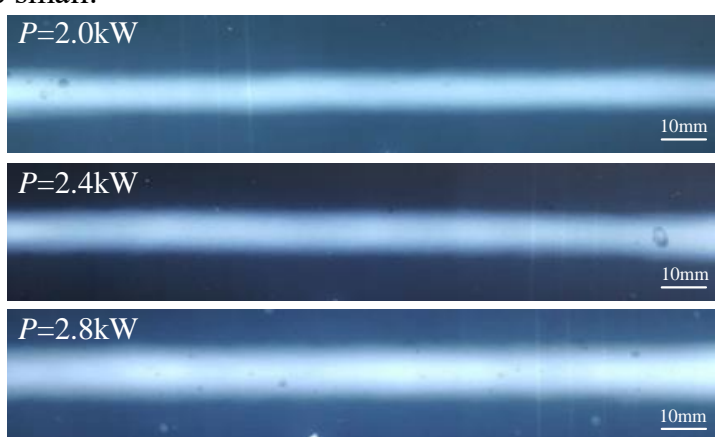

Fig. 3 Weld seam X-ray inspection under different laser power

It can be seen from the figure that as the laser power increases, the porosity of the weld decreases. As the 
laser power increases, the solidification time of the pool metal increases, resulting in an increase in the nitrogen evolution time. At the same time, the laser power increases, the keyhole effect becomes more intense, and the molten metal flowability increases.

\subsection{Influence of arc energy on the porosity of weld}

Fig. 4 and Fig. 5 are images of $\mathrm{X}$ - ray flaw detection of weld seam under different welding current and arc voltage. It can be obtained from the diagram that the porosity of the welding seam decreases with the increase of the welding current and the arc voltage. This is because when the arc energy is low, the effect of laser on arc compression and arc stabilization is obvious. The arc column becomes smaller, which leads to the decrease of weld width. Therefore, the area where bubbles escape from the molten pool becomes smaller. In addition, the arc energy becomes smaller, which causes the solidification time of the molten pool to become shorter. So bubbles do not have enough time to escape from the molten pool.

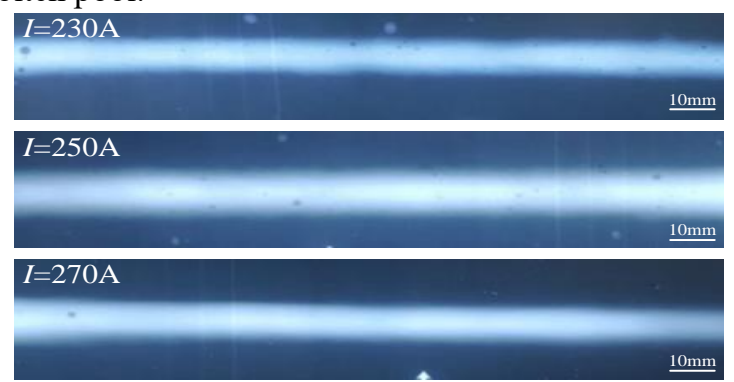

Fig. 4 Welding X-ray flaw detection diagram under different welding currents
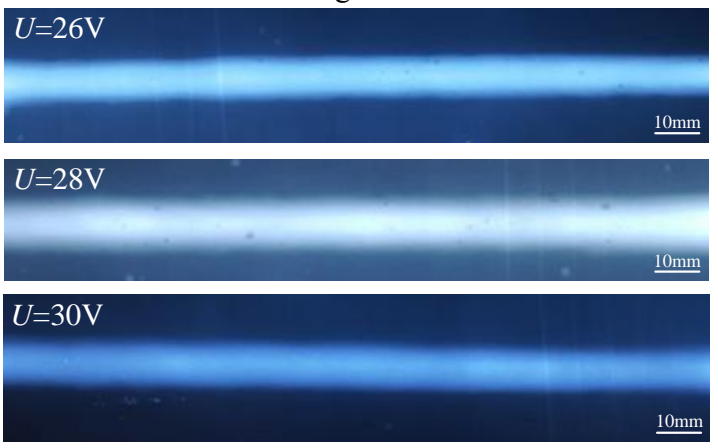

Fig. 5 Welding X-ray flaw detection diagram under different arc voltage

\subsection{Influence of welding speed on the porosity of weld}

Fig. 6 shows the weld X-ray flaw detection at different welding speeds. As can be seen from the figure, the porosity of the weld increases as the welding speed increases. This is due to the fact that as the welding speed increases, the line energy per unit length of the weldment decreases and the solidification time of the weld pool shortens, so the nitrogen escape time decreases.

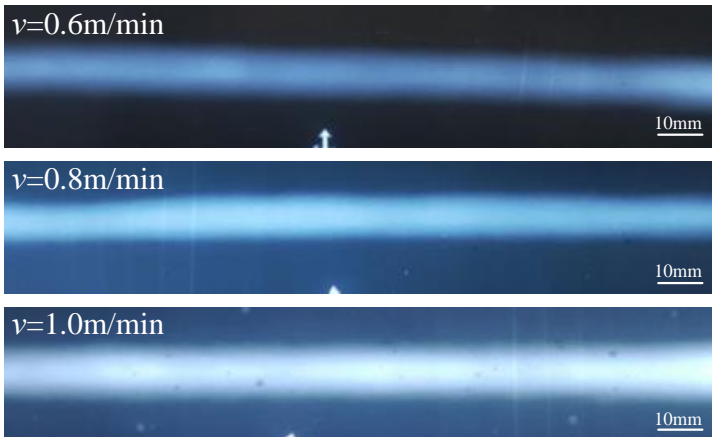

Fig. 6 Welding X-ray inspection under different welding speeds

\section{Conclusions}

In the welding process, nitrogen absorption and nitrogen release processes occur in the molten pool. With the increase of laser power, welding current and arc voltage, the porosity of the weld decreased; as the welding speed increased, the porosity of the weld increased.

\section{References}

1. HANS B. Manufacture and application of high nitrogen steels[J]. The Iron and Steel Institute of Japan, 1996, 36(7): 909-914

2. LI Dongjie, Lu Shanping, LI Dianzhong, et al. Investigation of the microstructure and impact properties of the high nitrogen stainless steel weld[J]. Acta Metallurgica Sinica, 2013, 49(2): 129-136.

3. YUJI I, RIKIO N. Effect of thermo-mechanical treatment on mechanical properties of high-nitrogen containing Cr-Mn-Ni austenitic stainless steels[J]. The Iron and Steel Institute of Japan, 1996, 36(7): 855-861

4. NAT M. Nitrogen containing austenitic stainless steels[J]. Materialwissenschaft Und Werkstofftechnik, 2006, 37(10): 875-880

5. LANG Yuping, QU Huapeng, CHEN Haitao, et al. Research progress and development tendency of nitrogen-alloyed austentic stainless Steel[J]. Journal of Iron and Steel Research, 2015, 22(2): 91-98.

6. STEIN G, HUCKLENBROICH I. Manufacturing and applications of high nitrogen steels[J]. Materials and Manufacturing Processes, 2004, 19(1): 7-17.

7. HERTZMAN S, WESSMAN S. An experimental and theoretical study of nitrogen flux in stainless steel TIG welds[J]. Materials Science Forum, 1999, 318- 320: 579- 590.

8. RAFFI M, G.Madhusudhan Reddy, K.Srinivasa Rao. Microstructure and pitting corrosion of shielded metal arc welded high nitrogen stainless steel[J]. Defence Techonology, 2015, 11(3): 237-243

9. WOO I, KIKUCHI Y. Weldability of high nitrogen stainless steel[J]. Transactions of JWRI. 2002, 31(2): 129-139. 
10. LI H B, JIANG Z H, FENG H, et al. Microstructure, mechanical and corrosion properties of friction stir welded high nitrogen nickel-free austenitic stainless steel[J]. Materials and Design, 2015, 84: 291-299.

11. KAMIYA O, CHEN Z W, KIKUCHI Y. Microporosity formation in partially melted zone during welding of high nitrogen austenitic stainless steels[J]. Journal of Materials Science, 2002, 37(12): 24752481.

12. GALLOWAY A M, MCPHERSON N A, BAKER $\mathrm{T} \mathrm{N}$. An evaluation of weld metal nitrogen retention and properties in 316LN austenitic stainless steel[J]. Proceedings of the Institution of Mechanical Engineers, Part L: Journal of Materials Design and Applications, 2011, 225(2): 61-69

13. ZHAO Lin, TIAN Zhiling, PENG yun, et al. Laser welding of high nitrogen steel $1 \mathrm{Cr} 22 \mathrm{Mn} 16 \mathrm{~N} \mathrm{I}$. Influence of shielding gas composition and heat input on N2 content and porosity of weld metal [J]. Transactions of the China Welding Institution, 2007, 28(8): 89-91.

14. MIYANO Y, FUJII H, SUN Yufeng, et al. Mechanical properties of friction stir butt welds of high nitrogen-containing austenitic stainless steel[J]. Materials Science and Engineering A, 2011, 528(6): 2917-2921.

15. SUN Shuo, LIU Shuangyu, JIA Dongsheng, et al. Multiple nonlinear regression model of weld bead shape for high nitrogen steel by laser-arc hybrid welding[J]. Journal of Mechanical Engineering, 2015, 51(8): 67-75.

16. WANG Lifeng, LIU Fengde, LIU Weina, et al. Study on control methods of welding porosity in laser-arc hybrid welding for high nitrogen steels[J]. Journal of Mechanical Engineering, 2016, 52(20): 51-59. 